\title{
A dimensão espacial na produção das culturas infantis: análise das interações entre meninas e meninos nos banheiros da Educação Infantil
}

\begin{abstract}
Resumo: Este artigo discute as relações de gênero que permeiam a organização e a utilização dos banheiros de uma instituição de Educação Infantil, por meio dos diferentes usos e apropriações que meninas e meninos cotidianamente fazem desses espaços. Considerando que os banheiros são espaços de alta densidade simbólica para a investigação das relações de gênero e sexualidade, este artigo problematiza e questiona as relações de poder presentes nessas manifestações. O escopo empírico que integra esta reflexão apoia-se numa etnografia realizada em uma instituição de Educação Infantil localizada na Região Metropolitana de São Paulo. Os resultados indicam um processo de espacialização sob a ótica de gênero, mostrando como o espaço configura-se como um importante elemento de controle das crianças, a partir da lógica adulta e pautado pelas estruturas de poder e desigualdades de gênero.A pesquisa identifica também uma profícua interação das crianças com os espaços dos banheiros, num movimento intenso de construção coletiva de estratégias para burlar e subverter a lógica binária e dicotômica de gênero segundo a qual esses espaços estão estruturados.
\end{abstract}

Palavras-chave: Espaço. Relações de Gênero. Banheiros. Educação Infantil.

\section{The spatial dimension of children's sociabilities: analysis of the interactions between girls and boys in the bathrooms of Child Educations}

\begin{abstract}
In this work, we will discuss the gender relations that permeate the organization and use of the bathrooms of an institution of Early Childhood Education, through the different uses and appropriations that girls and boys daily make of these spaces. Considering that bathrooms are spaces of symbolic high density for the investigation of gender relations and sexuality, we will question the power relations present in these manifestations. The empirical scope that integrates this reflection is based on an ethnography carried out in an institution located in the Metropolitan Region of São Paulo. The results indicate a spatialization process from a gender perspective, showing how space is an important element of children's control, based on adult logic and based on power structures. We identify a profitable interaction of children with the spaces of the bathrooms, in an intense movement of collective construction of strategies to circumvent and subvert the binary and dichotomous logic according to which these spaces are structured.
\end{abstract}

Keywords: Space. Gender Relations. Bathrooms. Childeducation.

\footnotetext{
1 Mestre em Educação pela Universidade Federal de São Paulo. Doutorando em Educação pela Universidade Estadual Paulista "Júlio de Mesquita Filho" e Supervisor Escolar na Prefeitura Municipal de São Paulo. E-mail: tassiojosedasilva@gmail.com

2 Doutor em Sociologia pela Universidade Estadual de Campinas. Professor Adjunto no Departamento Acadêmico de Linguagem e

Comunicação da Universidade Tecnológica Federal do Paraná. E-mail: wtlisboa@yahoo.com.br
} 


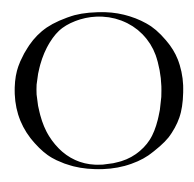

s espaços caracterizam-se como um quadro analítico que congrega as mais diferentes realidades, organizando e demarcando as posições ocupadas pelos sujeitos e pelas instituições corresponsáveis pelas narrativas que produzem o social, na sua complexidade. Essa perspectiva, originalmente explorada pelos estudos contemporâneos da área da Geografia Humana, dimensiona os espaços não somente por suas atribuições como unidade física passível de medição e representação cartográfica, mas também pela sua natureza como construto material e simbólico, fruto das relações de poder, das marcas das culturas impressas no solo e das subjetividades.

Partindo da premissa de que, na Educação Infantil, os espaços se configuram como lugares de afirmação das diferenças e também de combate às desigualdades, objetivamos, neste artigo, problematizar as relações de gênero que permeiam a organização e a utilização de um espaço específico, os banheiros de uma instituição pública de Educação Infantil, analisando a sua representatividade para meninas e meninos que dele fazem uso. Esse diálogo, calcado em embasamento teórico e constatações empíricas, nos conduz à reflexão sobre as maneiras como, na pequena infância, as relações sociais se (re)constituem e se legitimam segundo as práticas de apropriação espacial por parte das crianças pequenas.

A cidade onde a pesquisa de campo foi desenvolvida situa-se na Região Metropolitana de São Paulo (RMSP). No que toca ao atendimento da primeira etapa da Educação Básica (creches e pré-escolas), essa municipalidade conta com 24 escolas de Educação Infantil, sendo que a investigação ocorreu entre os meses de maio e dezembro de 2014, com uma frequência de três dias por semana, em uma das instituições da rede. Acompanhou-se o cotidiano das crianças da pré-escola, que frequentavam a instituição no período da manhã, e das crianças da creche, que permaneciam em período integral, fazendo uso dos diversos espaços da jornada educativa, entre eles: o hall de entrada, espaços internos e externos, refeitórios, salas, berçário, salas das turmas, além dos banheiros, separados por sexo, foco principal das problematizações apresentadas neste artigo.

À partida, é preciso frisar que as pesquisas que têm como objeto de análise a arquitetura escolar (LIMA, 1979; VIÑAO FRAGO e ESCOLANO, 2001) revelam o modo como os espaços influenciam as relações sociais nas instituições de educação a partir da sua própria materialidade, que expressa um amplo e variado conjunto de valores e simbologias determinado em diferentes contextos históricos, culturais, estéticos, ideológicos. Nesse sentido, as experiências vivenciadas pelas crianças no âmbito da Educação Infantil, inclusive as que são orientadas por construções de gênero, inter-relacionam-se a concepções hegemônicas de criança, educação e sociedade. 
Nessa linha de raciocínio, os estudos do campo da Sociologia da Infância, como as pesquisas de Delgado e Muller (2005) e de Faria e Finco (2011), entre outras, também nos oferecem a oportunidade de repensar as condições em que os conhecimentos e as identidades de meninas e meninos são produzidos no espaço e os lugares que as crianças ocupam nessa dinâmica. Os brinquedos e brincadeiras como esferas privilegiadas para a construção das identidades de gênero na infância (FINCO, 2004, 2010) são um exemplo do entrecruzamento de variáveis de diversa ordem que influenciam as culturas infantis. A partir da escolha de brinquedos, na interação entre as crianças e entre elas e os/as adultos/as, recriam-se e desconstroem-se múltiplos significados de gênero. Essas orientações de gênero também estão presentes nas manifestações artísticas e nas linguagens das crianças, como nos próprios desenhos que meninos e meninas produzem (GOBBI, 1997). Não por acaso, a docência masculina na primeira etapa da Educação Básica também é objeto de estudo de pesquisadores/as que apontam para as construções culturais do feminino e do masculino, muitas vezes respeitando uma lógica, bem articulada, de legitimação de estereótipos em torno das diferenciações de gênero (SAYÃO, 2005).

O presente texto intenciona, portanto, contribuir para o aprofundamento do conhecimento sobre os meninos e as meninas e a Educação Infantil, na construção de pedagogias emancipatórias, oferecendo pistas para um olhar refinado para os espaços e para a programação de práticas educativas que favoreçam o enfrentamento das desigualdades de gênero, desde os primeiros anos de vida. Acreditamos que a reflexão sobre os espaços coletivos de convívio entre as crianças e entre os/as adultos/as e crianças pode dar origem a uma pedagogia das diferenças, na qual as meninas e os meninos são protagonistas.

\section{Espaço, poder e gênero: múltiplas apropriações espaciais de meninas e meninos}

Os estudos que problematizam as formas de organização dos espaços e a arquitetura escolar (VIÑAO FRAGO e ESCOLANO, 2001; ZARANKIN, 2002) apontam para os modos como os espaços influenciam as relações sociais tecidas nos cotidianos das instituições de ensino. Em geral, reconhecem que a educação, como complexa atividade humana, possui uma dimensão temporal tanto quanto espacial, ambas atreladas a direcionamentos políticos, culturais, sociais e a seus constrangimentos.

Escolano (2001), por exemplo, destaca que a arquitetura escolar se configura como um programa discursivo que institui, na sua materialidade, um sistema de valores, concepções morais, estratégias de vigilância, ordem e controle, marcos para uma aprendizagem sensorial e para a afirmação de uma semiologia que se fundamenta em diferentes símbolos estéticos e ideológicos. O espaço-escola, nessa linha de análise, caracteriza-se como um construto sócio-histórico que, para além da sua estrutura física e por meio dela, funciona como um vetor propagador de discursos e, como tal, um mediador cultural. Com base na teoria social formulada por Giddens (1990), Escolano (2001) defende que a escola, ao mediar espacialmente as relações sociais, gera um poder disciplinar.

A "espacialização" disciplinar é parte integrante da arquitetura escolar e se observa tanto na separação das salas de aula (graus, sexo, características dos alunos) como na disposição regular das carteiras (com corredores), coisas que facilitam, além disso, a 
rotina das tarefas e a economia do tempo (GIDDENS,1990 apud ESCOLANO, 2001, p.190-191).

O processo de espacialização tem por objetivo, entre outros, organizar e controlar minuciosamente os movimentos e os gestos humanos, fazendo da escola um "continente" de poder, já que as relações institucionais e humanas "são capazes de tornar inteligíveis o poder político e suas manifestações espaciais", como postula um dos mais importantes teóricos da área da Geografia Humanaª, Claude Raffestin (1993, p. 31). Na concepção deste autor, as interações sociais ocorrem segundo a complexidade constitutiva dos lugares e dos tempos, e tal complexidade não se limita ao caráter físico-natural dos espaços, se bem que esse aspecto também é fundamental e influente na composição de realidades. Como produto histórico relacional, os espaços se formam e se transformam, isto é, são territorializados (RAFFESTIN, 1993) pelas experiências diárias compartilhadas numa rede de inter-relações hierarquicamente disposta.

O espaço escolar, formado por lógicas de construção, legitimação e negociação de sentidos, deve ser perspectivado, então, como um "lugar", já que se delineia no fluir da vida, nos nexos materiais e simbólicos estabelecidos, até mesmo por gerações, nas suas demarcações, como propõe Viñao Frago (2001).

Todo espaço é um lugar percebido. A percepção é um processo cultural. Por isso, não percebemos espaços, senão lugares, isso é, espaços elaborados, construídos. Espaços com significados e representações de espaços. Representações de espaço que se visualizam ou contemplam, que se rememoram ou recordam, mas que sempre levam consigo uma interpretação determinada. Uma interpretação que é o resultado não apenas da disposição material de tais espaços, como também de sua dimensão simbólica. Nada é melhor do que falar, nesse caso, do valor didático do símbolo, um aspecto a mais da dimensão educativa do espaço (VIÑAO FRAGO, 2001, p. 78).

A escola, como um lugar de disputa por significações, exprime discursos que variam de acordo com distintos contextos sociais, culturais, políticos. E é nesse ponto que ViñaoFrago (2001), assim como Escolano (2001), chama a atenção aos diversos elementos postos em cena na dimensão educativa dos espaços. Ou seja, como instâncias sobre as quais recaem interesses múltiplos e uma gama de concepções culturais, é evidente que os espaços também educam, influindo na forma como os indivíduos compõem as suas narrativas representacionais da vida, devendo ser um componente temático explorado nos currículos. Portanto, há um jogo de composição e recomposição cotidiana dos espaços, inclusive dos espaços da escola, que se revelam pela intencionalidade da sua estrutura física e também pelos usos e funções que se faz dessa materialidade.

Esse viés epistemológico nos conduz à análise do espaço como um construto sociocultural que transcende largamente a noção de uma estrutura física de natureza imutável; ao contrário, define-se como um campo de acepções e ressemantização no qual os sentidos são evidenciados e também relativizados, mesmo que poderes coercitivos possam enviesar os modos de apropriação espacial. Nos seus meandros,

\footnotetext{
${ }^{3}$ Sorre (2003, p. 13, grifo do autor) explica que, enquanto a Geografia Física estuda os elementos inertes e a Geografia Biológica se ocupa dos seres vivos, a Geografia Humana é a parte da Geografia Geral que trata dos homens e suas obras desde o ponto de vista de sua distribuição na superfície terrestre "[...] é uma descrição científica das paisagens humanas e de sua distribuição no globo. São duas definições que se correspondem e se complementam".
} 
numa correlação de forças nem sempre simétricas, põe-se em interação uma diversidade de grupos culturais cujas práticas sociais, entre elas, as que afiançam a reprodução e/ou a redefinição de identidades, são validadas porque projetadas coletivamente no solo, o "cimento" de experimentações. Significa dizer que os espaços apresentam um substrato de referências representacionais sobre o qual e com o qual se desencadeiam as dinâmicas de formação de subjetividades e do próprio processo centrado na educação.

Sob um enfoque geográfico, Raffestin (1993) pontua que a compreensão das sociabilidades e da produção material e simbólica levadas a cabo no dia a dia compartilhado pelos sujeitos e pelas instituições requer a avaliação das especificidades espaciais onde essas práticas se desenrolam e consubstanciam territórios do vivido. Do ponto de vista da arqueologia, Zarankin (2002), em sua obra Paredes que domesticam, arqueologia da arquitetura escolar capitalista: o caso de Buenos Aires, estudou as estruturas arquitetônicas da escola primária do ensino básico e a sua vinculação com o desenvolvimento do sistema capitalista. O autor identifica um processo de "arquitetorização" das sociedades, uma vez que a arquitetura funciona como uma "tecnologia do poder", um produto carregado de intenções, sendo que a arquitetura escolar, em particular, conforma espaços de socialização que não escapam à essa concatenação de interesses ideologicamente planejados.

A arquiteta Mayumi de Souza Lima (1989), no livro A criança e a cidade, também problematizou a organização dos espaços por aqueles que detêm o poder, em contraponto com a forma como são apropriados pelas crianças. A partir da ideia de espaço-ambiente, a autora expõe o processo de constituição do espaço físico, ou seja, o modo como ele adquire status de ambiente, atrelado às pessoas que nele vivem. Com base no registro dos diferentes usos espaciais protagonizados pelas crianças, esta pesquisadora se viu motivada a compreender os modos de organizar e distribuir os espaços, as possibilidades de movimentos, a nebulosidade das informações e até mesmo a falta de conforto ambiental, condições que estão a serviço da produção de adultos/as obedientes e disciplinados/as, limpos/as e destituídos/as de vontade própria, além de temerosos/as e receosos/as para explanar indagações.

É nesse sentido que Lima (1989) ressalta a co-responsabilidade dos/as adultos/as, ou melhor, a sua obsessão pelo controle no que diz respeito ao comportamento das crianças. Esta autora questiona esse cerceamento absoluto das possibilidades de ação das crianças no espaço, a fim de assegurar a sensação de segurança por parte dos/as adultos/as.

A liberdade da criança é a nossa insegurança, enquanto educadores, pais ou simples adultos, e, em nome da criança, buscamos a nossa tranquilidade, impondo-lhes o caminho da imaginação. A insegurança não diz respeito apenas ao medo de que as crianças fiquem expostas a possíveis perigos, pois estes são reais e podem ser controlados objetivamente; o medo maior é o do desconhecido, do novo que pode surgir na ação das crianças e que pode colocar-nos diante da necessidade de nos repensarmos enquanto profissionais, enquanto pessoas que dominam o saber e, portanto, o poder (LIMA, 1989, p. 11).

Esta pesquisadora conclui que os espaços representam um importante elemento de condicionamento das crianças para a vida adulta, consoante uma lógica pautada pelo exercício de reprodução das estruturas ideológicas do poder. De fato, há que se considerar que a potencialidade da ação independente e criativa das crianças na apropriação do espaço-ambiente tende a ser reprimida pelos 
adultos desde a primeira infância, quando já são tolhidas as possibilidades de livre manifestação dos seus anseios, comportamentos e da sua imaginação. No entanto, as experiências e o trabalho investigativo apontam para uma constatação deveras relevante: as crianças ressignificam os espaços.

As instituições de Educação Infantil, como lugares privilegiados onde se pode viver as infâncias, necessitam ser repensadas e reorganizadas de maneira que as crianças tenham a liberdade para participar ativamente da elaboração dos espaços e das práticas neles desenvolvidas, num processo que afiance a transposição de estruturas físicas que inibem suas expressões individuais e coletivas para lugares de infâncias, lugares de vida, de construção e partilha de sentidos múltiplos. "Assim, a pedagogia faz-se no espaço e o espaço, por sua vez, consolida a pedagogia" (FARIA, 2007, p.70), num esforço de rompimento com modelos rígidos de escola que conduz à criação e valorização das culturas infantis.

Faria (2007), no que toca a este debate, concorda que os espaços, tanto internos como externos, devem favorecer a independência das crianças, sendo seguros, mas não excessivamente protetores. Isso porque, por meio do discurso da segurança, muitas vezes se acaba restringindo as experiências das crianças e impedindo que elas ultrapassem as barreiras que os ambientes proporcionam. Esta pesquisadora faz alusão aos estudos de Anna Lia Galardini, que defende o seguinte ponto de vista:

Um espaço e o modo como ele é organizado resulta sempre das idéias, das opções, dos saberes das pessoas que nele habitam. Portanto, o espaço de um serviço voltado para as crianças traduz a cultura da infância, a imagem da criança, dos adultos que o organizaram; é uma poderosa mensagem do projeto educativo concebido para aquele grupo de crianças (GALARDINI, 1996 apud FARIA, 2007, p. 85).

Por sua vez, Ambrogi (2011) sublinha que a utilização dos espaços está estritamente relacionada à concepção de cultura em um dado tempo histórico e aos momentos reservados para o aprender, projetando assim o tipo de sujeito que se pretende formar. Esta pesquisadora aponta que a proposta dos usos espaciais pode favorecer o adestrar ou o educar, o domesticar ou o formar para a autonomia. A organização dos espaços na Educação Infantil, desse modo, influencia diretamente na forma como as crianças se relacionam e tanto indica o grau de intervenção do/a adulto/a quanto pode atestar o nível de liberdade e de decisão concedido às crianças. Os espaços dos quais se apropriam meninas e meninos, por exemplo, revelam as marcas interventivas cultural e institucionalmente. Ou melhor, a ideia do "espaço generificado" (WENETZ, 2005) nos ajuda a problematizar as configurações espaciais da divisão dos sexos e os prejuízos provocados no convívio diário, em sociedade.

Nessa linha de raciocínio, as pesquisas têm revelado que os critérios para a organização e uso dos espaços acabam por reforçar a separação entre meninas e meninos, ao estabelecer dinâmicas baseadas em disputa entre esses dois grupos (AUAD, 2004; FINCO, 2004, 2010). No espaço de creches e pré-escolas, as questões de gênero no cotidiano da Educação Infantil se expressam por meio do controle e da normatização dos corpos e, ainda, por diversas situações da rotina diária, nas quais os grupos são segregados. Assim, ao invés de proporcionar vivências que possibilitem a integração de meninas e meninos, tais orientações acabam por rivalizá-los, por vezes incentivando comparações e sentimentos competitivos. Para Prado (2006, p. 10), a "negação da possibilidade de modificar esta situação de 
segregação" endossa a condição de "subordinação e incapacidade de estabelecer múltiplas relações" entre as crianças.

Através da tentativa exaustiva de controle e de domínio das atividades [e dos corpos] das crianças, profissionais docentes e não docentes buscam definir um tempo, um espaço, um início, um fim, ditar os companheiros e objetos para e nas relações entre as crianças, não havendo, assim, possibilidades de reflexão sobre as atitudes e desejos demonstrados pelas crianças (PRADO, 2006, p. 10).

Essas fronteiras baseadas no sexo estão circunscritas nos diversos tempos e espaços que caracterizam as práticas pedagógicas em creches e pré-escolas. As filas separadas entre meninos e meninas, por exemplo, delimitam a arena de transição das crianças durante todo o dia: na entrada, na ida ao parque, no almoço, demonstrando que essa concepção tem como finalidade que as meninas sirvam de modelos de comportamento para os meninos. Nessa linha de entendimento, é evidente que

A prática educativa das "filas de meninas" e "filas de meninos" realizada cotidianamente vai confirmando os comportamentos das meninas para que sejam mais responsáveis, dedicadas, comunicativas, estudiosas, interessadas e sensíveis, e os meninos, para que as sigam como modelo. A prática da fila com os meninos vincula seus corpos aos seguintes comportamentos: são malandros, são dispersivos, são agitados (FINCO, 2010, p. 109).

As dinâmicas desenroladas na Educação Infantil, como verificado neste exemplo, contribuem significativamente para a construção e legitimação de papéis fixos de comportamentos para meninas e meninos, revelando que a própria configuração espacial, por si só, remete a uma mensagem que segrega e dicotomiza as crianças. Na pesquisa de Paz (2008), apesar de as professoras declararem que, nas atividades em grupo, as crianças se organizavam espontaneamente nos espaços, identificou-se que, na disposição das salas, sentavam pares de meninas e pares de meninos, o que levou a investigadora ao seguinte questionamento: se, nos demais espaços, como no parque e no momento da "rodinha" de conversa, as crianças sentavam juntas, por que exatamente nas atividades em grupo elas sentariam separadamente? Paz (2008) constatou que a estratégia adotada se caracterizava por separar as crianças mais agitadas daquelas mais tranquilas, mantendo, segundo nossa análise, o binômio meninos agitados - meninas quietas.

Os espaços da Educação Infantil e o modo como são organizados pode contribuir para a manutenção do status quo, reproduzindo relações de poder e de subordinação presentes na sociedade (BUFALO, 1997). Nessa perspectiva, compreender a importância das questões de gênero no âmbito da educação das crianças pequenas significa enxergar que, desde a tenra idade, as crianças são rodeadas de normas sociais que regulam, normatizam e hierarquizam os diferentes espaços que compõem as instituições de Educação Infantil. Essa dinâmica pode ser compreendida na organização dos banheiros e das filas, quando as relações implicam, em primeira ordem, a separação de meninas e meninos, tendo como norte uma naturalização de diferenças entre homens e mulheres, atreladas ao sexo e às características físicas, consideradas imutáveis. "O feminino e o masculino são apresentados em categorias opostas, excludentes e hierarquizadas, nas quais a mulher, os valores e os significados femininos ocupam posição inferior" (VIANNA e UNBEHAUM, 2004, p. 22). 
Cabe ressaltar que as explicações biologicistas em torno das diferenças entre homens e mulheres foram questionadas pelos movimentos feministas do final da década de 1960, que denunciaram as diversas formas de exclusão e discriminação às quais estavam submetidas as mulheres. Nos meandros da luta feminista e no desafio de constatar e explicitar que a anatomia não justifica as desigualdades de gênero, que se estabelecem pelas representações que as culturas imprimem nos corpos de homens e mulheres, meninas e meninos, na década de 1970 as feministas passaram a utilizar o termo "gênero", traduzido do inglês gender. Segundo Meyer (2013), as feministas pós-estruturalistas ressignificaram o conceito de gênero e problematizaram, ao mesmo tempo, as noções de corpo, sexo e sexualidade, introduzindo mudanças epistemológicas no âmbito desses estudos. Tal empreendimento foi deveras importante, pois desconstruir a distinção entre o natural e, por extensão, o biológico, no que se refere ao sexo, e o social, no que diz respeito ao gênero, foi e ainda é um recurso indispensável para que os estudos de gênero contribuam com a desmitificação de essencialismos que, há séculos, vêm sendo adotados para justificar e hierarquizar os corpos, as mentes e as representações, sobretudo, em torno do feminino.

O pensamento de que o sexo se refere apenas à anatomia e aos componentes fisiológicos lança possibilidades de questionamento de que homens e mulheres são diferentes nos campos comportamentais, cognitivos e sociais, pelas distinções apresentadas no cérebro, genes ou hormônios. Diante dessas interpretações, os estudos feministas reivindicam que os corpos não refletem, exclusivamente, os princípios da natureza, já que ela mesma também está calcada por valores de contextos históricos e sociais. Para Linda Nicholson (2000), o movimento feminista refuta o determinismo biológico, entendendo que as sociedades divergem no que se refere aos aspectos que produzem corpos. Isso não quer dizer que o corpo, como categoria de análise, desapareça na teoria feminista, pelo contrário, ele se torna uma variável que, embora importante, não é capaz de fundamentar as distinções entre masculino/feminino.

A padronização e a normatização de comportamentos sociais são, portanto, finalidades de uma ideologia dominante que, com base em supostas diferenciações sexuais biológicas, perpetuam modelos para o que é ser masculino ou feminino, de modo que os papéis atribuídos a cada categoria sejam percebidos pela sociedade de forma natural, óbvia e imutável. Para Joan Scott (1995), as relações de gênero baseiam-se nas particularidades percebidas entre homens e mulheres, além das diversas simbologias fornecidas pela cultura, reproduzidas espacialmente nas relações em coletividade. Assim, o conceito de gênero não se limita à visão comum sobre o masculino/feminino, mas enfatiza o caráter social das relações, na sua multidimensionalidade, com foco na construção histórica e não em algo já determinado a priori, tal como defende a perspectiva biologicista. "O gênero é uma forma primeira de significar as relações de poder" (SCOTT, 1995, p. 21). Nas instituições sociais, nas práticas cotidianas, nos rituais, as diferenciações de gênero estão presentes, perpassando discursos carregados de valores discriminatórios e modeladores de formas de representação e atuação de mulheres e homens no espaço. Isso reverbera desde o nascimento dos indivíduos, em um conjunto de símbolos e normas expressos por 
meio dos vínculos familiares, das instituições educativas, da mídia, entre outras instâncias socializadoras, que ditam as atitudes e comportamentos considerados adequados para cada sexo.

Logo, podemos pensar que o espaço físico compõe um importante aparato de disseminação de mensagens de gênero, apresentando conceitos normativos que separam e oferecem experiências diferenciadas a meninos e meninas. Essas mensagens estão presentes na materialidade dos diferentes espaços, nas paredes, nas cores, nos banheiros das instituições de Educação Infantil (SILVA, 2015), construindo comportamentos legitimados para cada sexo. Aliás, às crianças, esses modelos são repassados desde muito cedo.

\begin{abstract}
Vamos começar pelos bebês. As pessoas nascem machos e fêmeas e são criadas e educadas conforme o que a sociedade define como próprio de homem e de mulher: os adultos educam as crianças marcando diferenças bem concretas entre meninas e meninos. A educação diferenciada dá bola e caminhãozinho para os meninos e boneca e fogãozinho para as meninas, exige formas diferentes de se vestir, contar estórias em que os papéis dos personagens homens e mulheres são sempre muito diferentes. Outras diferenças aparecem de modo mais sutil, por aspectos menos visíveis, como atitudes, jeito de falar, pela aproximação com o corpo. (FARIA e NOBRE, 1997, p.01).
\end{abstract}

Relacionar gênero e infância, hoje, requer a compreensão atenta dos modos como as diferentes feminilidades e masculinidades são marcadas nos corpos de meninas e meninos, principalmente nos espaços da creche e pré-escola, e como essas simbologias impactam e contribuem na construção de suas identidades a partir das relações empreendidas espacialmente.

\title{
Relações de gênero no espaço: meninas e meninos nos banheiros da Educação Infantil
}

Por certo tempo tudo transcorre com tranquilidade. E então voltam os quatro meninos. Estão parados na porta, prontos para provocá-las. Marta pega um boneco que "faz xixi” e o aperta para espirrar um pouco de água na direção dos meninos. Federico chega perto da pia e abre a torneira ao máximo. Marta reclama, fecha a torneira, depois espirra água de novo com o boneco. Federico abre de novo a torneira ao máximo (STACCIOLI, 2013, p. 66).

A cena descrita acima, relatada no livro Diário de acolhimento na escola da infância, escrito por Gianfranco Staccioli (2013), apresenta a potencialidade e a multiplicidade de experiências que as crianças vivenciam nos espaços dos banheiros, no cotidiano da creche e da pré-escola. Na mesma direção, a pesquisa de Cruz (2011), em instituições de Ensino Médio, identifica nos espaços dos banheiros situações cotidianas para criar problematizações sobre a construção de identidades de gênero e suas possíveis implicações para a educação. Isso significa que os banheiros são espaços de alta densidade simbólica para a investigação das relações de gênero e sexualidade ${ }^{4}$ no contexto público e escolar, como similarmente constataram Gontijo, Eufrásio e Oliveira (2008, p. 45), ao investigar os sentidos transmitidos e negociados na apropriação desses espaços, como lugares em que ocorrem disputas identitárias e onde se "ratificam padrões conservadores de comportamento, abrigam escritas de erotismo e também de agressividade,

${ }^{4}$ Maria Cristina Cavaleiro (2009), ao investigar homossexualidades femininas na escola, discute o movimento de resistência de garotas que encontram no banheiro um "Iugar discreto", o único lugar da escola para a experiência, uma experiência discreta, separada, um espaço da escola reservado para a sexualidade menosprezada. 
hostilidade e obscenidade, além de usos pejorativos e de depreciação dos indivíduos" (GONTIJO; EUFRASIO e OLIVEIRA, 2008, p. 45).

Os banheiros, nas instituições de Educação Infantil, também legitimam concepções e práticas de cuidado do corpo orientadas segundo construções socioculturais, já que são locais atravessados por significados de sexo e gênero (TEIXEIRA e RAPOSO, 2007; SILVA, 2015). Nesse sentido, os usos espaciais também podem ocasionar momentos de conflitos entre as crianças e os adultos, situações que envolvem as dúvidas e as angústias dos adultos (famílias, professores e professoras) diante da originalidade que as crianças pequenas manifestam e vivenciam nesses espaços. Dúvidas sobre o uso dos banheiros mistos ou separados por gênero estão frequentemente presentes no cotidiano da Educação Infantil, em creches e pré-escolas, como atesta Silva (2015). É necessário questionar, pois, quais as normas e regras de gênero estão presentes nesta forma de separação, assim como perceber como a delimitação dos espaços influencia nas relações das crianças pequenas. Nesse embate, ancorado na cultura, na política, na educação, torna-se necessário observar os modos como se constroem e se reconstroem a posição da normalidade e a posição da diferença (LOURO, 2008), assim como os significados que lhes são atribuídos.

A organização dos espaços na instituição onde foi realizada a pesquisa de campo que também sustenta a presente discussão, na Região Metropolitana de São Paulo, compreende dois banheiros para o uso das crianças da creche e pré-escola, que são separados de acordo com o gênero, um para os meninos e outro, para as meninas.Verificamos uma profícua interação de meninos e meninas com os espaços dos banheiros, com o desejo de se relacionar, de conhecer o próprio corpo e o dos/das colegas, de brincar com água ou ficar sozinhos por alguns instantes. A partir de episódios observados empiricamente, numa perspectiva etnográfica, somados à aplicação de entrevistas em profundidade com professores e professoras da instituição, problematizaremos a organização e também a utilização desses espaços pelas crianças.

No cotidiano da Educação Infantil, como observado nesta investigação, as crianças subvertem certas lógicas normativas, operando com outros significados que não são compartilhados pelos adultos/as. O depoimento de uma das educadoras entrevistada é bastante elucidativo quanto à tentativa de imposição de padrões estabelecidos, apesar dos “desvios” na dinâmica de apropriação espacial por parte das crianças pequenas.

\footnotetext{
As meninas já sabem que o banbeiro é das meninas, e os meninos já sabem que o banbeiro é dos meninos, eles não se misturam. Se acontecer de um menino entrar no banbeiro das meninas, elas vêm correndo contar pra mim e, se uma menina entra no banbeiro dos meninos, ele vem correndo contar pra mim (Entrevista com a Educadora de Creche Marisa).

É já tem o banbeiro separado especiffico de menina, né? Já está bem caracterizado que é de menino e menina. Se você não falar nada pra criança, ela vai em qualquer um, então, desde o comeco, a gente fala...en falo, pelo fato de acompanbar. Então, elas já sabiam que era de menina. Comecei a perceber que eu deixava eles irem no banheiro e todos iam pro mesmo banbeiro, ai eu comecei a orientar, falar que as meninas eram de um lado e os meninos eram do outro (Entrevista com Marisa, Educadora de (reche).
}

De forma implícita, meninas e meninos são incentivados a se opor espacialmente, na medida em que se sentem valorizados a relatar os casos de utilização dos banheiros que não correspondem a uma 
lógica binária e heteronormativa. " $\mathrm{O}(\mathrm{s})$ banheiro(s) segue como dispositivo normalizador de gênero, lócus da reificação do(s) gênero(s), reprodutor da aura que determina os gêneros binários como rígidos opostos e incompatíveis" (PRECIADO, 2006, s/p.). Nessa trama, as crianças tornam-se os/as próprios/as fiscalizadores/as dessa vigilância, que objetiva a manutenção do status quo.

Foi possível perceber um processo de espacialização repleto de significados de poder, com a organização dos banheiros segundo uma função específica de controle e segregação entre os sexos.

Tal separação baseia-se no medo do adulto do despertar a sexualidade, em qualquer idade, pela visão do corpo e dos genitais, medo que se origina, por sua vez, numa concepção de natureza sexual que precisa ser reprimida. Nesse contexto cultural, a visão da sexualidade infantil situa-se na interseção entre a malícia e a ingenuidade da criança: mesmo sendo ingênua ela não é inocente (RAPOSO, 1999 apud TEIXEIRA e RAPOSO, 2007, p. 4).

Nessa linha de análise, podemos constatar que os espaços dos banheiros estão estritamente ligados ao corpo e à sexualidade das crianças, na medida em que apenas nesses espaços as crianças podem expressar a curiosidade de ver o corpo do/a outro/a ou mesmo saber o que tem dentro do banheiro visivelmente separado para o sexo oposto. Essa dimensão esteve presente durante todo o percurso investigativo.

O momento de escovar os dentes tem se evidenciado como uma oportunidade das crianças ficarem muito tempo sem a presença e controle do adulto/a. Neste sentido, as crianças escovam os dentes nas torneiras que ficam no pátio central e, nesta dinâmica, meninos e meninas sempre fingem que entraram nos banheiros uns dos outros. Parece-me que bá uma porta invisivel que os impedem de entrar. Na sequência, vejo um grupo de meninas na porta do banheiro dos meninos, elas riem e apontam para o Mickey, fingem que vão entrar, colocam o pé dentro, dão muitas risadas e depois voltam para a sala, pulando (Caderno de campo).

Assim, para as crianças, as regras de utilização dos banheiros se tornam uma desafiadora brincadeira, isto é, meninas e meninos brincam com essa "impossibilidade" de ultrapassar a fronteira e entrar nos banheiros contrários ao seu sexo. Desde muito pequenas, contudo, são ensinadas a se separar segundo esse mesmo modelo. Subverter essa lógica se torna uma experiência instigante às crianças.

Percebi nos movimentos das crianças nos espaços da instituição muitas cenas que evidenciavam a interação das crianças com os banheiros que fogem do controle e observação dos/as adultos/as. No pátio central, muitas crianças brincavam nos brinquedos grandes, e ao mesmo tempo as crianças de outras salas se direcionaram aos banheiros para escovar os dentes e outros cuidados. Neste momento, três meninos, rindo muito, entravam e saíam do banheiro. Possuiam uma expressão de felicidade e satisfação, entraram e saíram do banheiro inúmeras vežes, ou seja, aquele espaço estava livre para ser explorado (Caderno de campo).

No processo da pesquisa de campo chama-nos a atenção, como verificado na descrição acima, a ação das crianças na interação com os espaços dos banheiros, aproveitando-se da possibilidade de exploração territorial sem o controle direto dos adultos/as. As crianças, desse modo, reconfiguram o espaço dos banheiros quando exercem atividades diferentes daquelas que os adultos/as esperam que elas o façam. Compreendemos, nessa dinâmica, que por meio dos ajustes secundários (CORSARO, 2011), as crianças dão respostas às diversas regras e formas de controle exercidas pelas instituições. Ou seja, as crianças lançam mão de diversos mecanismos de ajuste para burlar a organização dos espaços, entre eles, os banheiros. 
Em sentido complementar, Ferreira (2004) assinala que, por meio dos ajustes secundários, é possível destacar os modos pelos quais é construída a vida íntima ou o submundo da instituição. Problematizar os ajustes secundários que as crianças acionam no cotidiano da creche e da pré-escola é fundamental para que possamos reposicionar o papel repressor que a instituição muitas vezes assume.

A professora disse às crianças que fossem ao banheiro e logo as alertou de que havia quatro espaços reservados, sendo que cada criança deveria utilizá-los individualmente. Logo em seguida, estávamos en e a professora na porta da sala esperando as crianças terminarem de utilizar os banbeiros, quando uma funcionária da limpeza veio até nós e disse que quatro meninos estavam utilizando o mesmo espaço. Assim que voltaram, a professora os interrogou dizendo que havia avisado que não poderiam utilizar o mesmo espaço reservado e que, diante deste fato, iria chamar a mãe deles para conversar. Neste momento, os meninos ficaram em silêncio e entraram para a sala. De volta a mim, a professora disse: "Só pode ser curiosidade!" (Caderno de Campo).

Os meninos, no banheiro, sem a supervisão da professora, expressaram a curiosidade e o desejo de compartilhar experiências, porém essa dimensão própria das crianças não foi compreendida pela professora, que, ao destacar que só poderia ser curiosidade, desconsiderou a capacidade inventiva e de burlar as regras quando as crianças estão no grupo de pares. No episódio acima, podemos visualizar claramente como o espaço dos banheiros pode se tornar local privilegiado para os ajustes secundários. As crianças conhecem a regra a que cada um deve atender nesse espaço específico, porém, na medida em que estão sozinhas e desejam compartilhar o mesmo local, se agrupam em um vaso sanitário. Por outro lado, vemos que esta ação foi reprovada pela professora, quando a funcionária da limpeza denunciou o descumprimento do combinado. Logo, como estratégia de inibição, a docente salientou que chamaria as mães para uma conversa, buscando corresponder e consolidar as orientações culturais então conhecidas entre os adultos.

O que se percebe é que os elementos das culturas infantis são produzidos por meninas e meninos, também, na interação com e nos banheiros, ou melhor, a partir das referências e dos desejos compartilhados espacialmente. Importante frisar que cultura infantil é aqui compreendida como sentidos culturais compartilhados pelas próprias crianças, que em certa medida também mantêm uma estreita relação com a cultura adulta. Para Corsaro (2011), meninos e meninas estão em constante integração e participação em duas culturas, a das crianças e a dos/as adultos/as, e essas culturas estão complexamente interligadas.

As experiências vivenciadas no interior dos banheiros se diferenciam substancialmente daquelas que se concretizam nos demais espaços, porque essa é a única ocasião em que as crianças estão livres dos olhos dos/as adultos/as por alguns instantes e, assim, podem vivenciar momentos singulares e expressar desejos e curiosidades. Nas imediações dos banheiros, inclusive, as crianças brincavam com o espelho que se situa no fim do corredor da instituição. "Uma intensa interação das crianças com o espelho grande que se encontra no corredor do banheiro, cotidianamente. Elas se olham, pulam, fazem caretas, brincam e interagem com o próprio corpo e dos colegas" (Caderno de campo).

Considerando os espaços como um elemento fundamental na Pedagogia da Educação Infantil, torna-se necessário garantir uma organização que respeite o direito à interação e à brincadeira como mola propulsora para novas experiências na infância. Como sublinha Faria (2007, p. 70), 
As instituições de Educação Infantil deverão ser espaços que garantam o imprevisto (e não a improvisação) e que possibilitarão o convívio das mais variadas diferenças, apontando para a arbitrariedade as regras (daí o jogo e a brincadeira serem tão importantes, iniciando o exercício da contradição, da provisoriedade e da necessidade de transformações).

Garantir o imprevisto e a individualidade das crianças nos espaços dos banheiros se constitui como um desafio para os/as profissionais da Educação Infantil. Um desafio ainda maior está em reconhecer, questionar e problematizar os "porquês" das normatizações dos espaços, compreender as curiosidades e os pontos de vista das crianças e, finalmente, reconhecer a organização dos espaços das instituições como importantes para a construção das identidades de gênero das crianças. Os espaços, enfim, devem permitir a livre expressão, o "maravilhamento", a descoberta e o respeito pelo próprio corpo e pelo corpo do outro.

\section{Considerações finais}

Ao analisarmos a reinterpretação dos significados e normas atribuídas ao uso dos banheiros pelas crianças foi possível verificar como a dimensão da curiosidade e da brincadeira esteve presente na interação das crianças nesses espaços. A lógica dos/as adultos/as, manifesta pela segregação espacial entre meninas e meninos, é interpelada pela lógica das crianças, curiosas quanto à sexualidade do outro. $\mathrm{O}$ cotidiano da pesquisa de campo evidenciou, contudo, que esta é apenas uma forma de sociabilidade e apropriação dos/nos banheiros, já que as crianças se valem de outras motivações, além da curiosidade pelo corpo, tais como brincar com água, conhecer o banheiro oposto ao que lhes é permitido, conversar com o amigo/a da outra sala ou apenas brincar, livremente.

Essas manifestações espaciais evidenciaram a necessidade de uma escuta atenta que possibilite compreender os pontos de vista e desejos das crianças e, assim, promover práticas que correspondam à necessidade de estarem juntas, de brincar, fantasiar mundos possíveis, para além dos estereótipos masculinos/femininos correspondentes ao modelo heteronormativo. Revelar como as relações de gênero estão presentes no cotidiano da creche e pré-escola significa, também, nos posicionarmos contra o movimento conservador que vem ganhando força por meio da retirada das pautas que envolvem gênero e diversidade no plano político federal e em muitos âmbitos estaduais e municipais. Tal panorama contraria os pressupostos apontados pela Constituição Federal de 1988, sem contar que é tarefa do Estado coibir mecanismos que reproduzem o sexismo, o machismo, a homofobia, a transfobia, entre outras formas de discriminação igualmente perniciosas.

Nessa perspectiva, organizar os espaços dos banheiros para além de uma lógica adultocêntrica requer estarmos abertos para as novidades que o olhar das crianças nos apresenta. Sua inventividade e protagonismo revelam-se como motores para uma organização espacial que promova as sociabilidades entre meninas e meninos. Neste panorama, a inclusão da temática de gênero nos Projetos Políticos Pedagógicos e, consequentemente, na formação continuada de professores/as e educadores/as se constituem como questões insurgentes para a efetiva promoção de práticas pedagógicas que fomentem a 
igualdade de gênero. Além disso, são necessárias para que se contraponham a modelos colonizadores de educação que segregam, reprimem,excluem e hierarquizam meninas e meninos.

\section{Referências}

AMBROGI, Ingrid Hotte. Reflexões sobre os usos do espaço como garantia para a criação de meninos e meninas pequenas. Pro-Posições, Campinas, v. 22, n. 2 (65), p. 63-73, maio/ago. 2011.

AUAD, Daniela. Relações de gênero nas práticas escolares e a construção de um projeto de co-educação. In: Reunião Anual da ANPEd, 27.,2004, Caxambu, Minas Gerais. Anais... Disponível em: <http://27reuniao.anped.org.br/ge23/t233.pdf>. Acesso em: 10 dez. 2016.

BUFALO, Joseane Maria P. Creche: lugar de criança, lugar de infância: um estudo sobre as práticas educativas em um CEMEI de Campinas. Dissertação (Mestrado em Educação) - Programa de PósGraduação em Educação. Universidade Estadual de Campinas, São Paulo, 1997.

CAVALEIRO, Maria Cristina. Feminilidades homossexuais no ambiente escolar: ocultamentos e discriminações vividas por garotas. Tese (Doutorado em Educação) - Programa de Pós-Graduação em Educação. Universidade de São Paulo, São Paulo, 2009.

CORSARO, William. Sociologia da Infância. Porto Alegre: Editora Artmed, 2011.

CRUZ, Elizabete Franco. Banheiros, travestis, relações de gênero e diferenças no cotidiano da escola. Revista Psicologia Política, São Paulo: Grupo de Estudos e Pesquisa em Psicologia Política, Políticas Públicas e Multiculturalismo da Universidade de São Paulo, vol.11, n.21, p. 73-90, 2011.

DELGADO, Ana Cristina Coll; MÜLLER, Fernanda. Sociologia da infância: pesquisa com crianças. Educação \& Sociedade, Campinas, São Paulo: Centro de Estudos Educação \& Sociedade, v. 26, n. 91, p. 351-360, mai./ago. 2005.

DUQUE, Tiago. "André, faz xixi de pé senão você vira mulher": diversidade sexual e formação de professores. In: Congresso Internacional sobre a diversidade sexual e de gênero da ABEH 6, Universidade Federal da Bahia, Anais......, Bahia, 2012.

ESCOLANO, Augustín. Arquitetura como programa. Espaço-escola e currículo. In: VIÑAO FRAGO, Antonio e ESCOLANO, Agustín. Currículo, espaço e subjetividade: a arquitetura como programa. Rio de Janeiro: DP\&A, 2001. 
FARIA, Ana Lúcia Goulart. O espaço físico como um dos elementos fundamentais para uma pedagogia da Educação Infantil. In: FARIA, Ana Lúcia Goulart e PALHARES, M. (Org.). Educação Infantil pós LDB. Campinas, São Paulo: Autores Associados, 2007. p. 67-97.

FARIA, Ana Lúcia Goulart; FINCO, Daniela (Orgs.). Sociologia da Infância no Brasil. Campinas, São Paulo: Autores Associados, 2011.

FARIA, Nalu; NOBRE, Mirian. O que é ser mulher? O que é ser homem?In: Subsídio para uma discussão das relações de gênero: gênero e desigualdade. Caderno Sempre viva, São Paulo: 1997, p.25 - 27. FERREIRA, Manuela. A gente gosta é de brincar com os outros meninos! Relações sociais entre crianças num jardim de infância. Porto: Edições Afrontamento, 2004.

FINCO, Daniela. Faca sem ponta, galinha sem pé, homem com homem mulher com mulher: relações de gênero na brincadeira de meninos e meninas na pré-escola. Dissertação (Mestrado em Educação) - Programa de Pós-Graduação em Educação. Universidade Estadual de Campinas, Campinas, 2004.

Educação Infantil, espaços de confronto e convívio com as diferenças: análise das interações entre professoras e meninas e meninos que transgridem as fronteiras do gênero. Tese (Doutorado em Educação) - Programa de Pós-Graduação em Educação. Universidade de São Paulo, São Paulo, 2010.

; GOBBI, Marcia; FARIA, Ana Lúcia Goulart de. Creche e feminismo: desafios atuais para uma educação descolonizadora. Campinas, SP: Edições Leitura Crítica; Associação de Leitura do Brasil ALB; São Paulo: Fundação Carlos Chagas - FCC, 2015.

GOBBI, Maria Aparecida. Lápis vermelho é de mulherzinha: relações de gênero, desenho infantil e educação infantil. Dissertação (Mestrado em Educação) - Programa de Pós-Graduação em Educação. Universidade Estadual de Campinas, Campinas, 1997.

GONTIJO, Isabela Barros Rabelo; EUFRASIO; Karen Nacostielle; OLIVEIRA, Manoel N. A. Usos sociais do espaço físico escolar. In: Congresso de Educação do Sudoeste Goiano, 24,Anais.... 2008.

LIMA, Mayumi Watanabe. de Souza. A criança e a percepção do espaço. Cadernos de pesquisa, Fundação Carlos Chagas, São Paulo, n.31, 1979, p.73-80.

LOURO, Guacira Lopes. Gênero e sexualidade: pedagogias contemporâneas. Pro-Posições, v. 19, n. 2 (56) - maio/ago. 2008. 
MARTINS, José de Souza. O massacre dos inocentes:a criança sem infância no Brasil. São Paulo: Editora Hucitec, 1989.

MEYER, Dagmar Estermann. Gênero e educação: teoria e política. In: LOURO, Guacira Lopes; FELIPE, Jane; GOELLNER, Silvana Vilodre (Orgs.). Corpo, gênero e sexualidade um debate contemporâneo na educação. 9 ed. São Paulo: Editora Vozes, 2013. pp 11-29.

NICHOLSON, Linda. "Interpretando o gênero". Revista Estudos Feministas, v. 8, n. 2, p. 9-41, 2000.

PAZ, Claudia Denis Alves da. Gênero no trabalho pedagógico da Educação Infantil. Dissertação (Mestrado em Educação) - Programa de Pós-Graduação em Educação. Universidade de Brasília, Distrito Federal, 2008.

PRADO, Patrícia Dias. Contrariando a idade: condição infantil e relações etárias entre crianças pequenas da Educação Infantil. Tese (Doutorado em Educação) - Programa de Pós-Graduação em Educação. Universidade Estadual de Campinas, São Paulo, 2006.

PRECIADO, Beatriz. Sujeira e Gênero: Mijar/Cagar, Masculino/Feminino. Disponível em: <http://www.myspace.com/doiscorpos/blog/276091123>. Acesso em: 10 abr. 2013.

RAFFESTIN, Claude. Por uma Geografia do poder. São Paulo: Ática, 1993.

SAYÃO, Deborah Thomé. Relações de gênero e trabalho docente na Educação Infantil: Um estudo de professores em creche. Tese (Doutorado em Educação) - Programa de Pós-Graduação em Educação. Universidade Federal de Santa Catarina, Florianópolis, 2005.

SCOTT, Joan. Gênero: uma categoria útil de análise histórica. Educação e Realidade, Porto Alegre, Rio Grande do Sul: Faculdade de Educação da Universidade Federal do Rio Grande do Sul, vol. 20, n. 2, p. 71-99, jul./dez. 1995.

SORRE, Max. Nossos clássicos. GEOgraphia, Niterói, v. 10, n. 5, p.135-136, out. 2003.

SILVA, Tássio José da. Organização e utilização dos espaços físicos na Educação Infantil: um estudo sob a ótica do gênero. Dissertação de Mestrado - Programa de Pós-Graduação em Educação, Universidade Federal de São Paulo - Guarulhos, 2015.

STACCIOLI, Gianfranco. Diário do acolhimento na escola da infância. Campinas, São Paulo: Autores Associados, 2013. 
TEIXEIRA, Adla B. Martins; RAPOSO, Ana Elvira S. Silva. Banheiros escolares: promotores de diferenças de gênero. In: Reunião Anual da Anped, 30. Caxambu, Minas Gerais, 2007. Anais.....Disponível em: < http://30reuniao.anped.org.br/trabalhos/GT23-3472--Int.pdf > . Acesso em: 8 jun. 2015.

VIANNA, Claudia; UNBEHAUM, Sandra. Gênero e políticas públicas de educação: impasses e desafios para a legislação educacional brasileira. In: SILVEIRA, M. L.; GODINHO, T. (Orgs.). Educar para a igualdade: Gênero e educação escolar. São Paulo: Coordenadoria Especial da Mulher, Secretaria Municipal de Educação, 2004. pp 19-48. VIÑAO FRAGO, Antonio e ESCOLANO, Augustín. Currículo, espaço e subjetividade. Rio de Janeiro: DP\&A, 2001.

WENETZ, Ileana. Gênero e sexualidade nas brincadeiras do recreio. Dissertação (Mestrado em Ciência do Movimento Humano) - Programa de Pós-Graduação em Ciência do Movimento Humano. Escola de Educação Física, Universidade Federal do Rio Grande do Sul, Porto Alegre, 2005.

ZARANKIN, A. Paredes que domesticam: arqueologia da arquitetura escolas capitalistas: o caso de Buenos Aires. São Paulo: FAPESP, 2002. 